\title{
Association of Single Nucleotide Polymorphisms in a Disintegrin and Metalloproteinase 12 Gene With Susceptibility to Knee Osteoarthritis: A Meta-Analysis
}

\author{
Jae Hyun JUNG ${ }^{1,2} \mathbb{D}$, Gwan Gyu SONG ${ }^{1,2} \mathbb{D}$, Jae-Hoon $\mathrm{KIM}^{1,2} \mathbb{D}$, Sung Jae CHOI ${ }^{1,3}$ \\ ${ }^{1}$ Department of Internal Medicine, Korea University College of Medicine, Seoul, South Korea \\ ${ }^{2}$ Department of Rheumatology, Korea University Guro Hospital, Seoul, South Korea \\ ${ }^{3}$ Department of Rheumatology, Korea University Ansan Hospital, Ansan, South Korea
}

\begin{abstract}
Objectives: This study aims to investigate the association between a disintegrin and metalloproteinase 12 polymorphisms and susceptibility to knee osteoarthritis (OA) through a meta-analysis involving only studies that present original data.

Materials and methods: A meta-analysis was performed on the association between a disintegrin and metalloproteinase 12 rs3740199, rs1871054, rs 1278279 and rs1044122 polymorphisms and knee OA. An electronic search of all relevant studies published up to January 2017 was conducted using MEDLINE and EMBASE. The study included six case-control studies including 2,966 patients (850 males, 2,116 females) with knee OA and 4,901 controls (2,286 males, 2,615 females).

Results: No significant association was found between the rs3740199, rs1278279, and rs1044122 polymorphisms and knee OA when all studies were pooled into the meta-analysis. However, a significant association was found between the rs1871054 polymorphism and the knee OA risk (allele contrast: odds ratio $(O R)=1.42,95 \%$ confidence interval $(C l)=1.02-1.98, p=0.04$; dominant: $O R=1.36,95 \% C l=1.02-1.82, p=0.04$; recessive: $O R=1.83,95 \%$ $\mathrm{Cl}=1.14-2.94, \mathrm{p}=0.01$; and addictive model: $\mathrm{OR}=1.85,95 \% \mathrm{Cl}=1.06-3.23, \mathrm{p}=0.03)$. In the subgroup analysis, a significant association was found between the recessive $(\mathrm{OR}=0.44,95 \% \mathrm{Cl}=0.21-0.93, \mathrm{p}=0.03)$ and addictive model $(\mathrm{OR}=0.29,95 \% \mathrm{Cl}=0.12-0.69, \mathrm{p}<0.01)$ in the male group.

Conclusion: Our meta-analysis suggests that the rs 1871054 polymorphism is associated with susceptibility to knee OA and that the GG genotype of rs3740199 was associated with knee OA in the male group. Additional well-designed studies are required to confirm these results.

Keywords: ADAM12; osteoarthritis; polymorphism.
\end{abstract}

Osteoarthritis (OA) is the most common arthritis in old age. The knee is the second most frequent location of occurrence of $\mathrm{OA}$ after the hand. ${ }^{1}$ Knee $\mathrm{OA}$ is a disease that causes pain and disability, and may eventually require surgical treatment. Knee OA is known to occur mainly as a degenerative condition, but metabolic and genetic factors have also been implicated. Several genetic polymorphisms, including growth differentiation factor 5 and double von Willebrand factor domain A gene, have been shown to be associated with susceptibility to knee OA. ${ }^{2,3}$ However, the polymorphisms of several genes, such as angiotensin-converting enzyme, have been found to be unrelated to the susceptibility to knee OA. ${ }^{4}$

A disintegrin and metalloproteinase 12 (ADAM12), the gene of which has been identified as a candidate gene for knee $\mathrm{OA}$, plays role

Received: November 10, 2017 Accepted: February 02, 2018 Published online: August 16, 2018

Correspondence: Sung Jae Choi, MD. Department of Rheumatology, Korea University Ansan Hospital, 15355 Ansan, South Korea. Tel: +82-2-2626-1130 e-mail: csjmd888@korea.ac.kr 
in proteolysis, cellular interactions, and signal transduction. ${ }^{5}$ After Valdes et al. ${ }^{6}$ published a study on the association of ADAM12 polymorphisms with knee OA, several studies were conducted at other centers. Among single nucleotide polymorphisms (SNPs) of ADAM12, rs3740199 was the main polymorphism studied. In addition, studies on SNPs of rs187054, rs1278279, and rs1044122 were conducted. However, each study reported different results. Several meta-analyses have been conducted to date, however, the studies involved in each meta-analysis are different, resulting in multiple conclusions. ${ }^{7-10}$ Thus, in this study, we aimed to investigate the association between ADAM12 polymorphisms and susceptibility to knee OA through a meta-analysis involving only studies that present original data.

\section{MATERIALS AND METHODS}

A literature search was performed at Korea University Guro Hospital between December 2016 and July 2017 for studies that examined associations between ADAM12 polymorphisms and knee OA. In MEDLINE and EMBASE, searches were performed through the following search terms: (ADAM12 OR a disintegrin and metalloproteinase 12) AND (knee osteoarthritis OR knee OA OR degenerative arthritis) AND (polymorphisms OR variant OR mutation OR genotype) up to January 2017. A manual search was also performed for related studies. The study included six case-control studies including 2,966 patients (850 males, 2,116 females) with knee OA and 4,901 controls (2,286 males, 2,615 females).

The studies included in the meta-analysis met the following criteria: (i) case-control studies that determined the distributions of ADAM12 polymorphisms and susceptibility to knee OA, and (ii) detailed data were reported in case and control groups, or could be calculated from data provided. The following studies were excluded from the meta-analysis: (i) overlapping data, (ii) the number of null and wild-type genotypes or alleles could not be ascertained, and (iii) only abstracts, case reports, or review articles. There were no restrictions on race, language, ethnicity, or geographic area.

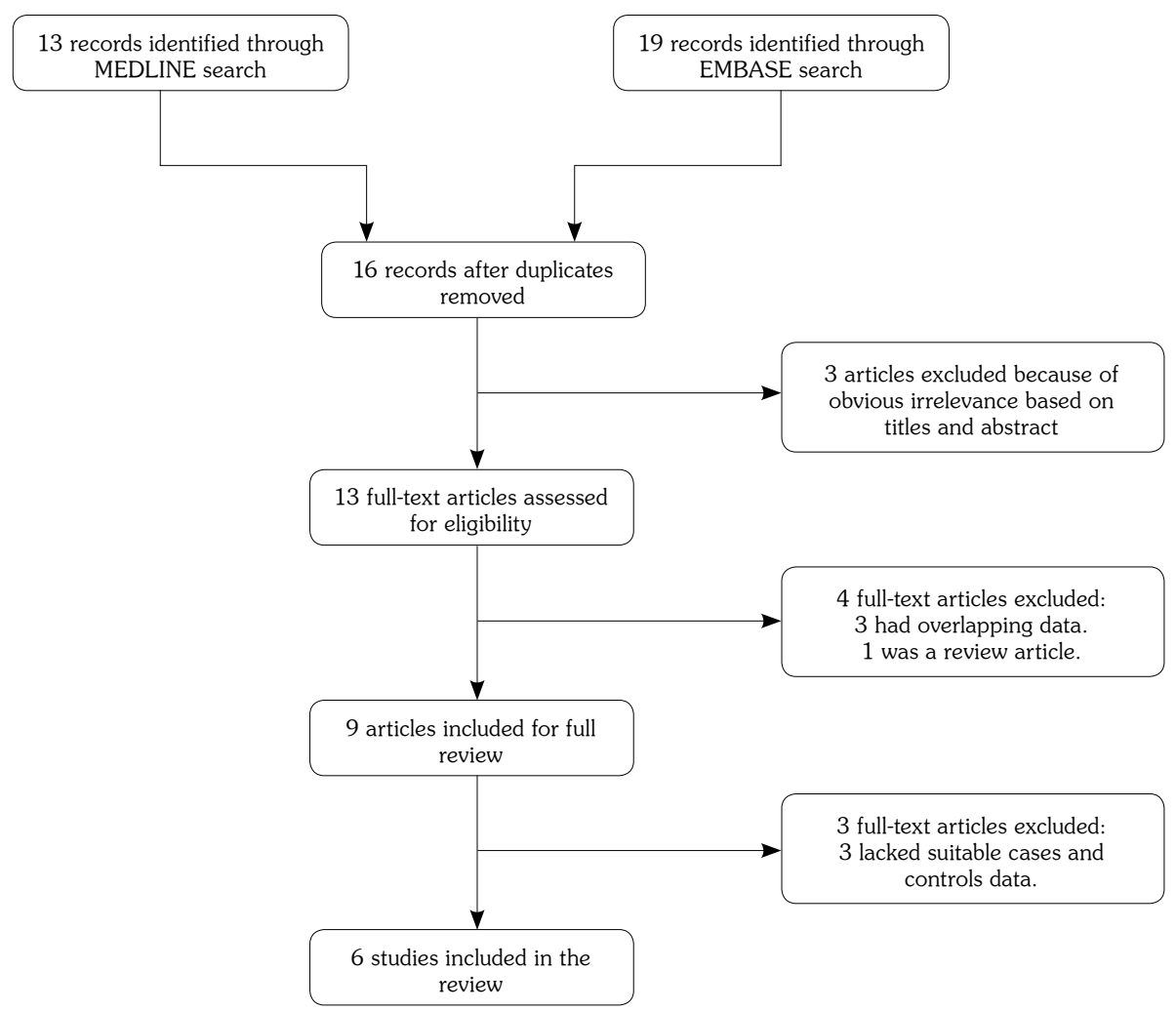

Figure 1. Flow-chart of application of inclusion/exclusion criteria. 
The baseline information was extracted, such as the first author, year of publication, country and sex of the study population, type and grade of $\mathrm{OA}$ in case groups, number of cases and controls, results of the Hardy-Weinberg equilibrium (HWE) test, and allele and genotype frequencies of ADAM12. In cases of duplicated publications from the same study group, the study with a larger sample size was retained. This meta-analysis was conducted based on the Preferred Reporting Items for Systematic Reviews and Meta-Analyses (PRISMA) guidelines. ${ }^{11}$

\section{Statistical analysis}

We used the allele counting method to determine the allele frequencies of ADAM12 polymorphisms. The relationships between the ADAM12 polymorphisms and susceptibility to knee OA were estimated using odds ratios (ORs) and 95\% confidence intervals (CIs). The significance of pooled ORs was determined by the Z-test and $p$ values $<0.05$ were considered statistically significant. The pooled ORs were calculated for the allele contrast, dominant and recessive model, and addictive model.

The heterogeneity between studies was assessed by Cochran Q test. Heterogeneity was considered significant at a $p$ value $<0.10$ or $I^{2}$ values $\geq 50 \%$. If there was no significant study heterogeneity, a fixed-effect model was used, otherwise a random-effect model used. Forest plots were drawn to visualize the overall effect. Potential publication bias was estimated using funnel plots. Meta-analysis was performed using Review Manager 5.3 (The Nordic Cochrane Center, The Cochrane Collaboration, 2014).

\section{RESULTS}

A total of 32 published articles were found through an electronic search. Of these, 16 articles were duplicated and, by browsing the title and abstract, three were excluded because of obvious irrelevance. After a full-text review, a further seven

Table 1. Characteristics of individual studies included in systemic review and meta-analysis

\begin{tabular}{|c|c|c|c|c|c|c|c|}
\hline First author & Year & Country & Gene & Sex & $\begin{array}{c}\text { Number of } \\
\text { case }\end{array}$ & $\begin{array}{l}\text { Number of } \\
\text { control }\end{array}$ & $\begin{array}{c}\text { Definition of } \\
\text { OA }\end{array}$ \\
\hline Poonpet et al. ${ }^{12}$ & 2016 & Thailand & rs3740199 & $\begin{array}{l}\mathrm{F} \\
\mathrm{M}\end{array}$ & $\begin{array}{l}147 \\
53\end{array}$ & $\begin{array}{c}149 \\
51\end{array}$ & $G \geq 1^{*}$ \\
\hline Wang et al. ${ }^{13}$ & 2015 & China & $\begin{array}{l}\text { rs3740199 } \\
\text { rs1871054 } \\
\text { rs1278279 } \\
\text { rs1044122 }\end{array}$ & $\mathrm{F}+\mathrm{M}$ & 164 & 200 & $\mathrm{G} \geq 2$ \\
\hline Lou et al. ${ }^{14}$ & 2014 & China & $\begin{array}{l}\text { rs3740199 } \\
\text { rs1871054 } \\
\text { rs1278279 } \\
\text { rs1044122 }\end{array}$ & $\mathrm{F}+\mathrm{M}$ & 152 & 179 & $\mathrm{G} \geq 2$ \\
\hline Shin et al. ${ }^{15}$ & 2012 & Korea & rs3740199 & $\mathrm{F}+\mathrm{M}$ & 725 & 1737 & $G \geq 2$ \\
\hline \multirow[t]{2}{*}{ Kerna et al. ${ }^{16}(1)$} & 2009 & Estonia & $\begin{array}{l}\text { rs3740199 } \\
\text { rs1871054 }\end{array}$ & $\mathrm{F}$ & 51 & 88 & $\mathrm{G} \geq 2, \mathrm{TFJ}$ \\
\hline & & & & M & 15 & 35 & \\
\hline Kerna et al. ${ }^{16}(2)$ & 2009 & Estonia & $\begin{array}{l}\text { rs3740199 } \\
\text { rs1871054 }\end{array}$ & $\begin{array}{l}\mathrm{F} \\
\mathrm{M}\end{array}$ & $\begin{array}{l}72 \\
25\end{array}$ & $\begin{array}{l}67 \\
25\end{array}$ & $\mathrm{G} \geq 2, \mathrm{PFJ}$ \\
\hline Rodriguez-Lopez et al. ${ }^{17}(1)$ & 2009 & Spain & rs3740199 & $\begin{array}{l}\mathrm{F} \\
\mathrm{M}\end{array}$ & $\begin{array}{l}422 \\
102\end{array}$ & $\begin{array}{l}230 \\
358\end{array}$ & TKR \\
\hline Rodriguez-Lopez et al. ${ }^{17}(2)$ & 2009 & UK & rs3740199 & $\begin{array}{l}\mathrm{F} \\
\mathrm{M}\end{array}$ & $\begin{array}{c}278 \\
40\end{array}$ & $\begin{array}{l}274 \\
112\end{array}$ & TKR \\
\hline Rodriguez-Lopez et al. ${ }^{17}$ (3) & 2009 & Greece & rs3740199 & $\begin{array}{l}\mathrm{F} \\
\mathrm{M}\end{array}$ & $\begin{array}{l}392 \\
328\end{array}$ & $\begin{array}{l}712 \\
684\end{array}$ & TKR \\
\hline
\end{tabular}


(a)

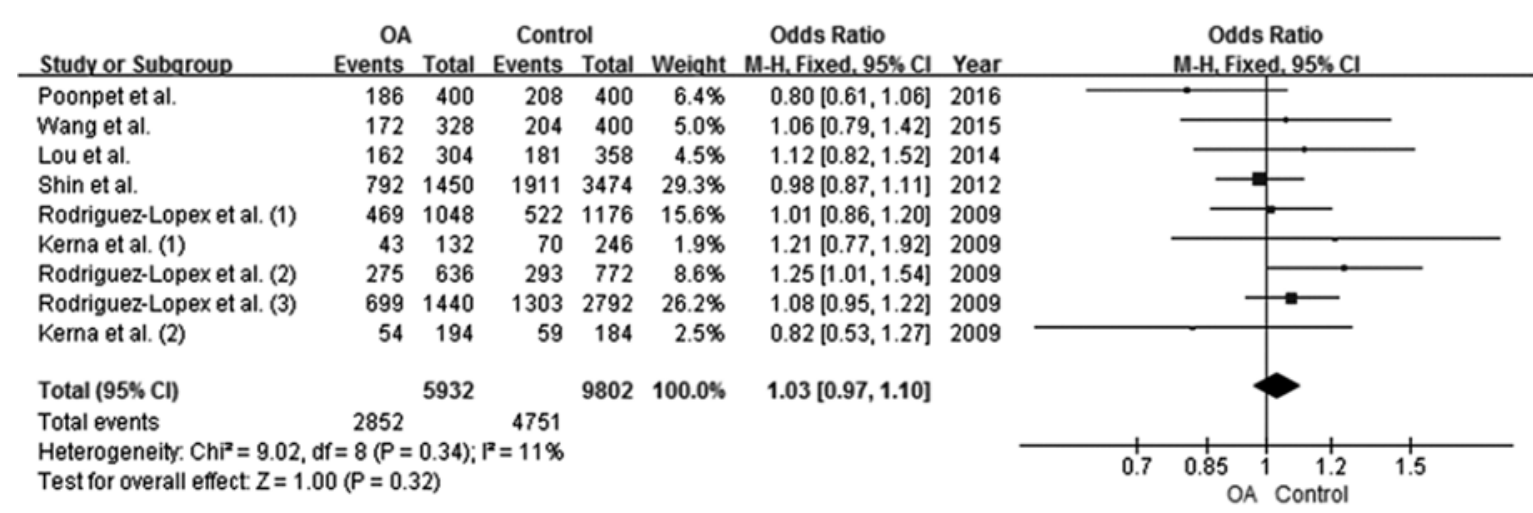

(b)

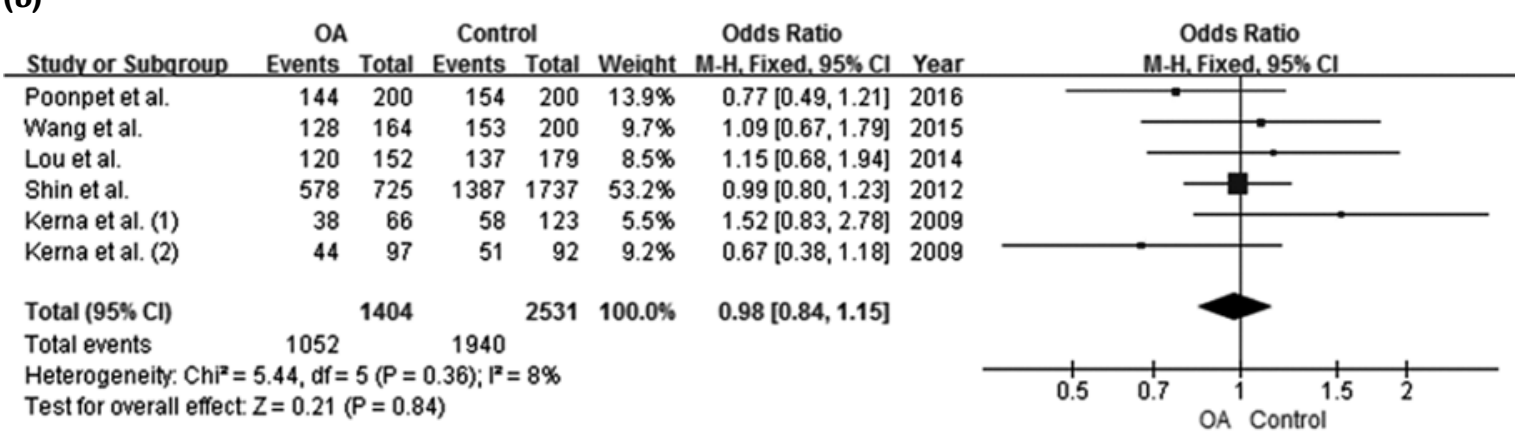

(c)

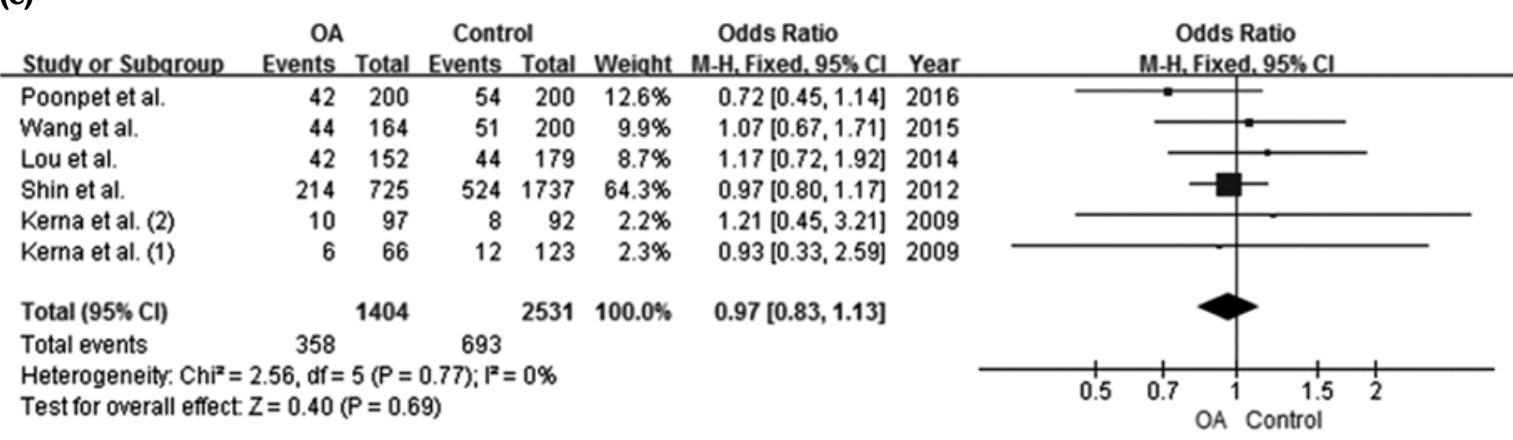

(d)

OA Control Odds Ratio Odds Ratio

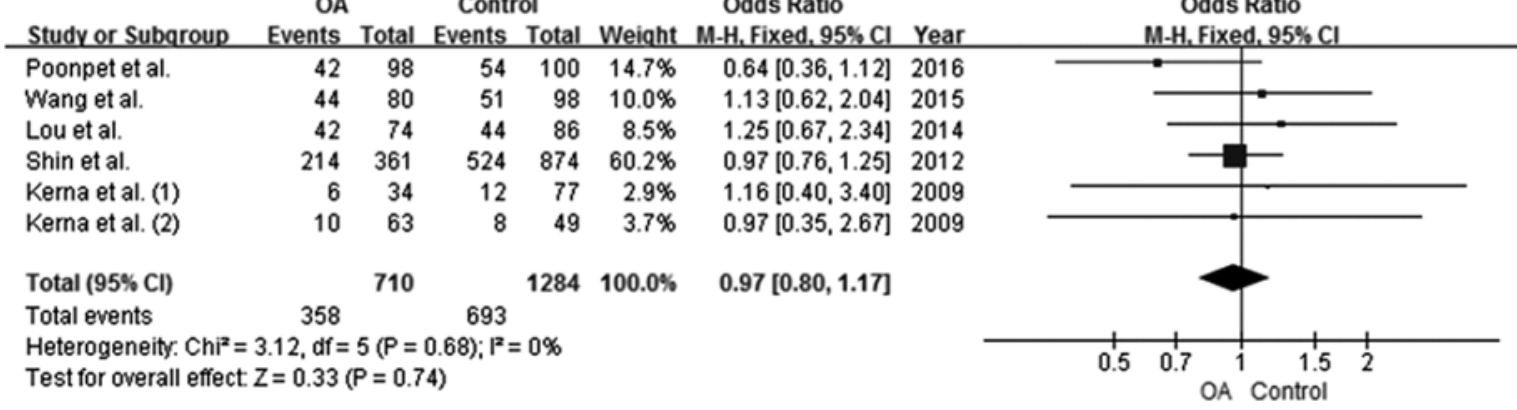

Figure 2. Forest plots of rs3740199 C/G polymorphisms and susceptibility to knee osteoarthritis. (a) Allele contrast, (b) dominant, (c) recessive, and (d) addictive model. OA: Osteoarthritis; CI: Confidence interval. 
Table 2. Meta-analysis of association between ADAM12 polymorphisms and susceptibility to knee osteoarthritis

\begin{tabular}{|c|c|c|c|c|c|c|c|}
\hline \multirow[b]{2}{*}{ Comparison } & \multirow[b]{2}{*}{ Population } & \multirow[b]{2}{*}{$\begin{array}{l}\text { Number of } \\
\text { studies }\end{array}$} & \multicolumn{2}{|c|}{ Test of association } & \multirow[b]{2}{*}{ Mode } & \multicolumn{2}{|c|}{ Heterogeneity } \\
\hline & & & OR (95\% CI) & $p$ & & $I^{2}(\%)$ & $p$ \\
\hline \multicolumn{8}{|l|}{ rs3740199 } \\
\hline \multirow[t]{5}{*}{ G vs. C } & Overall & 9 & $1.03(0.97-1.10)$ & 0.32 & $\mathrm{~F}$ & 11 & 0.34 \\
\hline & Female & 6 & $1.11(0.99-1.23)$ & 0.07 & $\mathrm{~F}$ & 0 & 0.73 \\
\hline & Male & 6 & $0.92(0.63-1.35)$ & 0.67 & $\mathrm{R}$ & 77 & $<0.01$ \\
\hline & Asian & 4 & $0.98(0.89-1.08)$ & 0.69 & $\mathrm{~F}$ & 0 & 0.40 \\
\hline & European & 5 & $1.08(0.99-1.18)$ & 0.09 & $\mathrm{~F}$ & 1 & 0.40 \\
\hline \multirow[t]{4}{*}{ CG+GG vs. $C C$} & Overall & 6 & $0.98(0.84-1.15)$ & 0.84 & $\mathrm{~F}$ & 8 & 0.36 \\
\hline & Female & 3 & $1.14(0.80-1.62)$ & 0.46 & $\mathrm{~F}$ & 0 & 0.47 \\
\hline & Male & 3 & $0.44(0.17-1.15)$ & 0.09 & $\mathrm{R}$ & 55 & 0.11 \\
\hline & Asian & 4 & $0.98(0.83-1.17)$ & 0.84 & $\mathrm{~F}$ & 0 & 0.64 \\
\hline \multirow[t]{4}{*}{ GG vs. $C G+C C$} & Overall & 6 & $0.97(0.83-1.13)$ & 0.69 & $\mathrm{~F}$ & 0 & 0.77 \\
\hline & Female & 3 & $1.03(0.65-1.63)$ & 0.89 & $\mathrm{~F}$ & 31 & 0.23 \\
\hline & Male & 3 & $0.44(0.21-0.93)$ & 0.03 & $\mathrm{~F}$ & 0 & 0.39 \\
\hline & Asian & 4 & $0.97(0.83-1.13)$ & 0.66 & $\mathrm{~F}$ & 0 & 0.50 \\
\hline \multirow[t]{4}{*}{ GG vs. CC } & Overall & 6 & $0.97(0.80-1.17)$ & 0.74 & $\mathrm{~F}$ & 0 & 0.68 \\
\hline & Female & 3 & $1.14(0.67-1.94)$ & 0.63 & $\mathrm{~F}$ & 0 & 0.37 \\
\hline & Male & 3 & $0.29(0.12-0.69)$ & $<0.01$ & $\mathrm{~F}$ & 43 & 0.17 \\
\hline & Asian & 4 & $0.96(0.79-1.18)$ & 0.70 & $\mathrm{~F}$ & 0 & 0.39 \\
\hline \multicolumn{8}{|l|}{ rs1871051 } \\
\hline \multirow[t]{2}{*}{$\mathrm{C}$ vs. $\mathrm{T}$} & Overall & 4 & $1.42(1.02-1.98)$ & 0.04 & $\mathrm{R}$ & 72 & 0.01 \\
\hline & Asian & 2 & $1.85(1.49-2.30)$ & $<0.01$ & $\mathrm{~F}$ & 0 & 0.98 \\
\hline \multirow[t]{2}{*}{$\mathrm{TC}+\mathrm{CC}$ vs. TT } & Overall & 4 & $1.36(1.02-1.82)$ & 0.04 & $\mathrm{~F}$ & 14 & 0.32 \\
\hline & Asian & 2 & $1.68(1.16-2.43)$ & $<0.01$ & $\mathrm{~F}$ & 0 & 0.89 \\
\hline \multirow[t]{2}{*}{$\mathrm{CC}$ vs. TC+TT } & Overall & 4 & $1.83(1.14-2.94)$ & 0.01 & $\mathrm{R}$ & 65 & 0.03 \\
\hline & Asian & 2 & $2.61(1.89-3.60)$ & $<0.01$ & $\mathrm{~F}$ & 0 & 0.90 \\
\hline \multirow[t]{2}{*}{ CC vs. TT } & Overall & 4 & $1.85(1.06-3.23)$ & 0.03 & $\mathrm{R}$ & 60 & 0.06 \\
\hline & Asian & 2 & $2.81(1.84-4.27)$ & $<0.01$ & $\mathrm{~F}$ & 0 & 0.96 \\
\hline \multicolumn{8}{|l|}{ rs1278279 } \\
\hline A vs. $G$ & Overall (Asian) & 2 & $1.08(0.84-1.38)$ & 0.54 & $\mathrm{~F}$ & 0 & 0.96 \\
\hline $\mathrm{GA}+\mathrm{AA}$ vs. $\mathrm{GG}$ & Overall (Asian) & 2 & $1.19(0.88-1.61)$ & 0.27 & $\mathrm{~F}$ & 0 & 0.95 \\
\hline AA vs. $G A+G G$ & Overall (Asian) & 2 & $0.83(0.45-1.53)$ & 0.56 & $\mathrm{~F}$ & 0 & 0.89 \\
\hline AA vs. GG & Overall (Asian) & 2 & $0.88(0.47-1.62)$ & 0.67 & $\mathrm{~F}$ & 0 & 1.00 \\
\hline \multicolumn{8}{|l|}{ rs1044122 } \\
\hline C vs. T & Overall (Asian) & 2 & $0.95(0.77-1.18)$ & 0.66 & $\mathrm{~F}$ & 0 & 0.84 \\
\hline $\mathrm{TC}+\mathrm{CC}$ vs. TT & Overall (Asian) & 2 & $1.01(0.73-1.39)$ & 0.97 & $\mathrm{~F}$ & 0 & 0.95 \\
\hline $\mathrm{CC}$ vs. $\mathrm{TC}+\mathrm{TT}$ & Overall (Asian) & 2 & $0.84(0.56-1.26)$ & 0.39 & $\mathrm{~F}$ & 0 & 0.77 \\
\hline CC vs. TT & Overall (Asian) & 2 & $0.87(0.55-1.37)$ & 0.54 & $\mathrm{~F}$ & 0 & 0.80 \\
\hline
\end{tabular}

ADAM12: A disintegrin and metalloproteinase 12; OA: Osteoarthritis; OR: Odds ratio; CI: Confidence interval; R: Random-effects model; F: Fixed-effects model. 
(a)

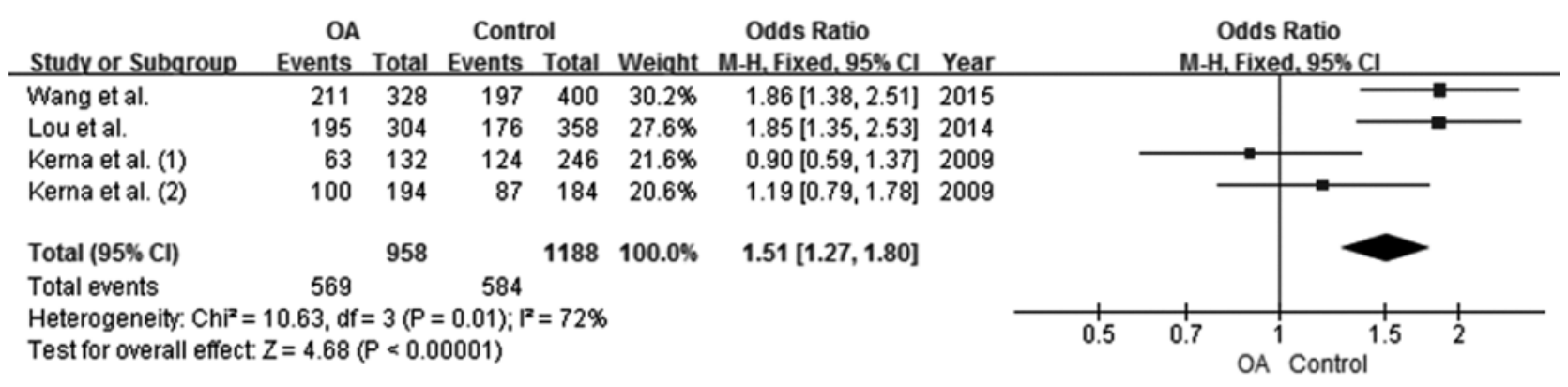

(b)

\begin{tabular}{|c|c|c|c|c|c|c|c|c|c|c|c|}
\hline Study or Subaroup & $\begin{array}{l}\mathrm{OA} \\
\text { Events }\end{array}$ & Total & $\begin{array}{l}\text { Contr } \\
\text { Events }\end{array}$ & $\begin{array}{l}\text { ol } \\
\text { Total }\end{array}$ & Weight & $\begin{array}{c}\text { Odds Ratio } \\
\text { M-H, Fixed, } 95 \% \mathrm{Cl}\end{array}$ & Year & & $\begin{array}{r}\text { Odds } \\
\text { M-H, Fixe }\end{array}$ & $\begin{array}{l}\text { Ratio } \\
\text { ed, } 95 \% \mathrm{Cl}\end{array}$ & \\
\hline Wang et al. & 135 & 164 & 148 & 200 & $29.7 \%$ & $1.64[0.98,2.73]$ & 2015 & & & & \\
\hline Lou et al. & 126 & 152 & 132 & 179 & $26.1 \%$ & $1.73[1.01,2.95]$ & 2014 & & & & \\
\hline Kerna et al. (2) & 73 & 97 & 68 & 92 & $21.8 \%$ & $1.07[0.56,2.07]$ & 2009 & & & & \\
\hline Kerna et al. (1) & 48 & 66 & 93 & 123 & $22.3 \%$ & $0.86[0.44,1.70]$ & 2009 & & & & \\
\hline Total $(95 \% \mathrm{Cl})$ & & 479 & & 594 & $100.0 \%$ & $1.36[1.02,1.82]$ & & & & & \\
\hline Total events & 382 & & 441 & & & & & & & & \\
\hline \multicolumn{8}{|c|}{$\begin{array}{l}\text { Heterogeneity. Chi }=3.50, d f=3(P=0.32) ; I^{2}=14 \% \\
\text { Test for overall effect: } Z=2.10(P=0.04)\end{array}$} & 0.5 & $0.7 \mathrm{OA}^{1}$ & $1 \frac{1.5}{\text { Control }}$ & 2 \\
\hline
\end{tabular}

(c)

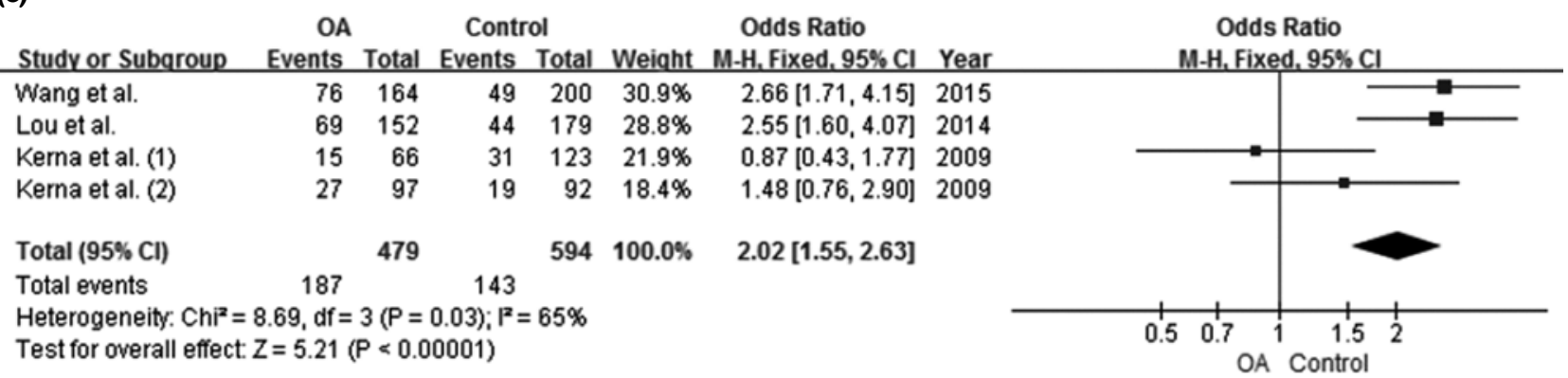

(d)

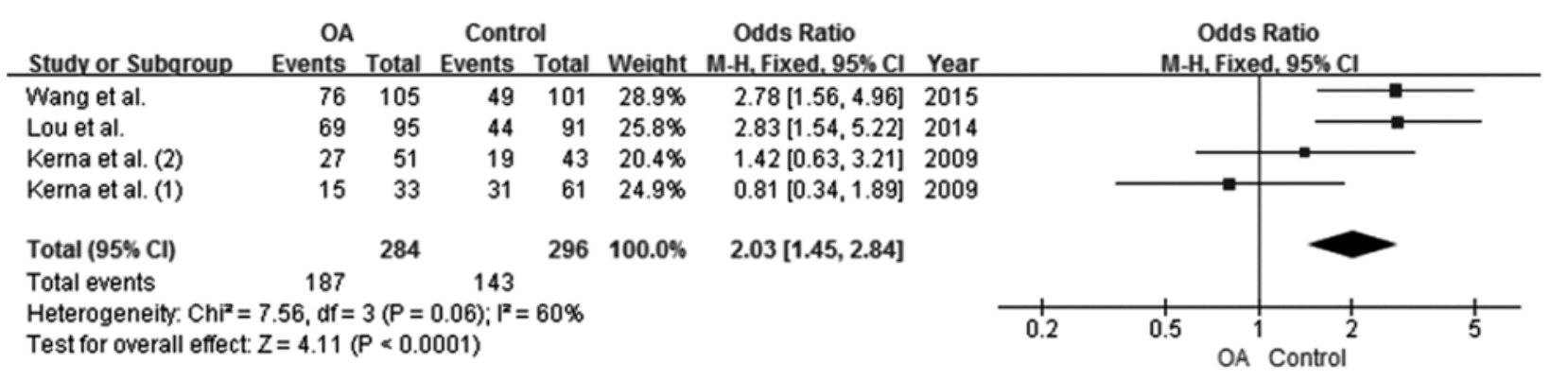

Figure 3. Forest plots of rs 1871054 T/C polymorphisms and susceptibility to knee osteoarthritis. (a) Allele contrast, (b) dominant, (c) recessive, and (d) addictive model. OA: Osteoarthritis; CI: Confidence interval. 
articles were removed: three had overlapping data, one was a review, and three did not report sufficient data. Additional eligible studies were not found through manual search. Figure 1 outlines the selection process of this meta-analysis. Finally, six case-control studies focusing on four ADAM12 polymorphisms (rs3740199, rs1871054, rs1278279, and rs1044122) and knee OA risk were included in this meta-analysis. ${ }^{12-17}$ Among them, since one study was conducted at three centers $^{17}$ and one study analyzed tibiofemoral joint and patellofemoral joint OA separately, ${ }^{16}$ a total of nine studies included 2,966 cases and 4,901 controls. Four studies were conducted on Asian subjects and five studies were conducted in European subjects. Details of the ADAM12 polymorphism studies evaluated in this metaanalysis are summarized in Table 1.

The meta-analysis suggested that the rs3740199 C/G polymorphism was not associated with susceptibility to knee OA in all genetic models in the overall populations: allele contrast $(\mathrm{OR}=1.03,95 \% \mathrm{CI}=0.97-1.10, \mathrm{p}=0.32)$; dominant $\quad(\mathrm{OR}=0.98, \quad 95 \% \quad \mathrm{CI}=0.84-1.15$, $\mathrm{p}=0.84)$; recessive $(\mathrm{OR}=0.97,95 \% \mathrm{CI}=0.83-1.13$, $\mathrm{p}=0.69) ;$ and addictive model (OR=0.97, 95\% $\mathrm{CI}=0.80-1.17, \mathrm{p}=0.74$ ) (Figure 2). The rs3740199 $\mathrm{C} / \mathrm{G}$ polymorphisms were analyzed by subgroup according to sex and geographic area. There was a significant association between the recessive $(\mathrm{OR}=0.44,95 \% \mathrm{CI}=0.21-0.93, \mathrm{p}=0.03)$ and addictive model $(\mathrm{OR}=0.29,95 \% \mathrm{CI}=0.12-0.69$, $\mathrm{p}<0.01)$ in the male group, but not in the remaining subgroups (Table 2).

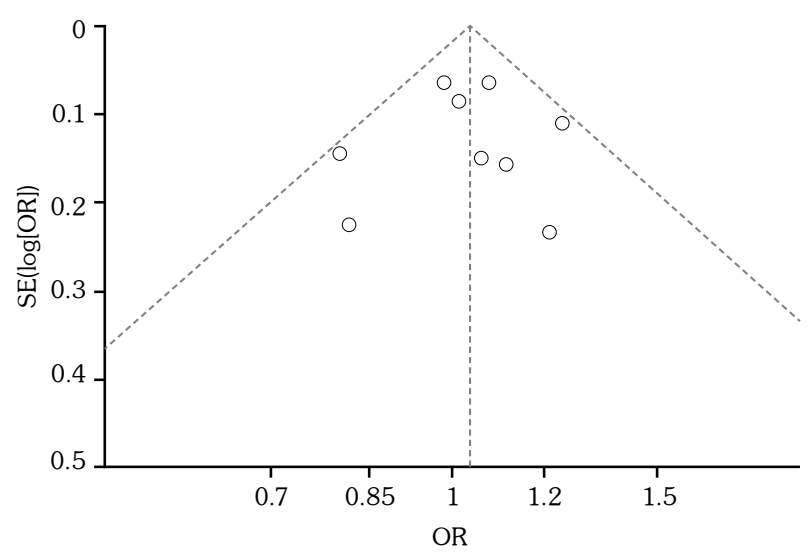

Figure 4. Funnel plots for knee osteoarthritis and rs3740199 C/G polymorphisms. SE: Standard error; OR: Odds ratio.
The meta-analysis showed that the rs1871054 $\mathrm{T} / \mathrm{C}$ polymorphism was significantly associated with susceptibility to knee OA in all genetic models in the overall populations: allele contrast (OR=1.42, 95\% $\mathrm{CI}=1.02-1.98, \mathrm{p}=0.04)$; dominant (OR=1.36, 95\% $\mathrm{CI}=1.02-1.82, \mathrm{p}=0.04)$; recessive $(\mathrm{OR}=1.83,95 \% \mathrm{CI}=1.14-2.94, \mathrm{p}=0.01)$; and addictive model $(\mathrm{OR}=1.85,95 \% \mathrm{CI}=1.06-3.23$, $p=0.03$ ) (Figure 3). Subgroup analysis, which focused on Asian populations owing to the limited number of included studies, indicated that there was a significant association between all genetic models (Table 2).

Both rs1278279 G/A and rs1044122 T/C polymorphisms were covered in two studies, all of which were of Chinese subjects and were not related to the susceptibility to knee OA.

There was significant heterogeneity in allele contrast and dominant model in the male group of rs37401099 C/G polymorphisms. There was also significant heterogeneity in allele contrast and recessive model in the overall population of $\mathrm{rs} 1871054 \mathrm{~T} / \mathrm{C}$ polymorphisms. These were analyzed using the random-effect model, and the rest were analyzed using the fixed-effect model. In addition, all of the included studies were found to be in HWE.

To assess possible publication bias, a funnel plot was used for rs37401099 C/G polymorphisms. The funnel plot was symmetrical in rs37401099 $\mathrm{C} / \mathrm{G}$ polymorphisms (Figure 4). However, we did not draw funnel plots in the meta-analysis for rs1871054 T/C, rs1278279 G/A, and rs1044122 $\mathrm{T} / \mathrm{C}$ since there were less than five studies included.

\section{DISCUSSION}

A disintegrin and metalloproteinase is a family of proteolytic enzymes regulating extra cellular matrix turnover in cartilage. ${ }^{14}$ ADAM12, a member of the ADAM gene family, resides on chromosome $10 \mathrm{q} 26$ and encodes a metalloprotease. ${ }^{12}$ ADAM12 is associated with synovial inflammation, overexpressed in OA cartilage, and reported to be associated with knee OA. ${ }^{16,18}$ In addition, ADAM12 is associated with the remodeling of bones and degradation of insulin-like growth factor-binding protein 5 in 
the cartilage. ${ }^{14}$ Thus, ADAM12 affects cartilage proliferation and bone growth.

The most studied polymorphism of the ADAM12 is rs3740199 C/G. This meta-analysis found that $\mathrm{rs} 3740199 \mathrm{C} / \mathrm{G}$ polymorphisms were not significantly associated with knee OA. When analyzed separately for Asian and Europeans, the rs3740199 C/G polymorphism was not found to be associated with the susceptibility to knee OA. However, as in the previous metaanalyses, ${ }^{8,9}$ our study showed that rs3740199 polymorphisms were associated with knee OA in males. In the subgroup analyzed for sex, the GG genotype in males showed less knee OA than $\mathrm{CG}+\mathrm{CC}$ or $\mathrm{CC}$ genotypes. These genetic polymorphisms, which are only associated with knee $\mathrm{OA}$ in male group, can explain sex differences in knee OA incidence. The prevalence of knee $\mathrm{OA}$ is higher in females than in males, because it is known to be associated with hormonal factors, structural differences, and differences in the rate of loss of cartilage. ${ }^{19}$ Genetic differences between males and females may also be included as a factor influencing the prevalence of knee OA.

A disintegrin and metalloproteinase 12 has also been associated with tendon homeostasis. ${ }^{20}$ However, the rs3740199 C/G polymorphism did not appear to be associated with Achilles tendon pathology. ${ }^{21}$ Although ADAM12 is thought to affect the pathogenesis of musculoskeletal diseases, the rs3740199 $\mathrm{C} / \mathrm{G}$ polymorphism is assumed to have little effect and studies on ADAM12 polymorphisms at several different loci have been conducted.

As in a previous meta-analysis, ${ }^{8}$ rs 1871054 $\mathrm{T} / \mathrm{C}$ was found to be significantly associated with knee OA in the overall and Asian populations. $\mathrm{T}$ allele has been suggested to be associated with an increased risk of knee OA. The rs1278279 $\mathrm{G} / \mathrm{A}$ and $\mathrm{rs} 1044122 \mathrm{~T} / \mathrm{C}$ polymorphisms were included in only two studies and were not found to be associated with knee OA.

In addition to ADAM12, studies have been conducted on a disintegrin metalloproteinase with thrombospondin motifs (ADAMTS) family closely related to the ADAM family, and a ADAMTS4 and ADAMTS5 have been identified as candidate genes to be associated with OA. ${ }^{22,23}$ Various biochemical markers related to OA have been found, indicating that $\mathrm{OA}$ is not simply a disease caused by degenerative factors. ${ }^{24}$

Unlike previous meta-analyses, we only included studies that confirmed the original data for four candidate polymorphisms of the ADAM12 gene and excluded studies conducted in the same institution to minimize bias. In addition, our study involved a subgroup analysis based on ethnicity and sex. However, there are some limitations to this meta-analysis. First, the criteria for defining knee OA were different for each study. Most studies classified knee OA as Kellgren-Lawrence Grade 2 or higher whereas Kellgren-Lawrence Grade 1 or higher was classified as knee OA in one study, ${ }^{12}$ and patients undergoing total knee replacement were classified as knee OA in three centers of one study. ${ }^{17}$ Since the disease severity and genetic factors may be relevant, differences between case groups may have affected the result of meta-analysis. Second, the number of studies included in the meta-analysis was small, except for the rs3740199 C/G polymorphism. A metaanalysis involving a small number of cases may be a limitation in deriving universal conclusions. More case-control studies are needed in the future on the association of rs1871054 T/C polymorphisms with knee OA. Third, other clinical data, such as age and occupation were not considered in this meta-analysis. Finally, although the funnel plot indicated no remarkable publication bias, some publication bias may exist in the results.

In conclusion, our meta-analysis demonstrated that ADAM12 rs3740199 C/G polymorphisms are not associated with knee OA susceptibility. However, the GG genotype of rs3740199 was found to be relevant in the male group. ADAM12 rs1871054 T/C polymorphism was significantly associated with knee OA susceptibility, but rs1278279 G/A and rs1044122 T/C polymorphisms were not. Further studies are warranted to determine whether these polymorphisms are associated with the risk of knee OA.

\section{Declaration of conflicting interests}

The authors declared no conflicts of interest with respect to the authorship and/or publication of this article.

\section{Funding}

The authors received no financial support for the research and/or authorship of this article. 


\section{REFERENCES}

1. Litwic A, Edwards MH, Dennison EM, Cooper C. Epidemiology and burden of osteoarthritis. Br Med Bull 2013;105:185-99.

2. Wang $\mathrm{T}$, Liang $\mathrm{Y}, \mathrm{Li} \mathrm{H}, \mathrm{Li} \mathrm{H}, \mathrm{He} \mathrm{Q}$, Xue $\mathrm{Y}$, Shen $\mathrm{C}$, et al. Single Nucleotide Polymorphisms and Osteoarthritis: An Overview and a Meta-Analysis. Medicine (Baltimore) 2016;95:2811.

3. Jiang D, Hao Z, Fan D, Guo W, Xu P, Yin C, et al. Association between GDF5 $+104 \mathrm{~T} / \mathrm{C}$ polymorphism and knee osteoarthritis in Caucasian and Asian populations: a meta-analysis based on case-control studies. J Orthop Surg Res 2016;11:104.

4. Lin C, Chen HC, Fang WH, Wang CC, Peng YJ, Lee HS, et al. Angiotensin-Converting Enzyme Insertion/Deletion Polymorphism and Susceptibility to Osteoarthritis of the Knee: A Case-Control Study and Meta-Analysis. PLoS One 2016;11:e0161754.

5. Kveiborg M, Albrechtsen R, Couchman JR, Wewer UM. Cellular roles of ADAM12 in health and disease. Int J Biochem Cell Biol 2008;40:1685-702.

6. Valdes AM, Hart DJ, Jones KA, Surdulescu G, Swarbrick P, Doyle DV, et al. Association study of candidate genes for the prevalence and progression of knee osteoarthritis. Arthritis Rheum 2004;50:2497-507.

7. Lv ZT, Liang S, Huang XJ, Cheng P, Zhu WT, Chen AM. Association between ADAM12 Single-Nucleotide Polymorphisms and Knee Osteoarthritis: A MetaAnalysis. Biomed Res Int 2017;2017:5398181.

8. Hu X, Sun G, Wang W. Association of ADAM 12 polymorphisms with the risk of knee osteoarthritis: meta-analysis of 5048 cases and 6848 controls. Rheumatol Int 2017;37:1659-66.

9. Wu Z, Xu XW, Zhang XW. The association of ADAM12 polymorphism with osteoarthritis susceptibility: a meta-analysis. Ther Clin Risk Manag 2017;13:821-30.

10. Hao Z, Li X, Dai J, Zhao B, Jiang Q. Genetic effects of rs3740199 polymorphism in ADAM12 gene on knee osteoarthritis: a meta-analysis. J Orthop Surg Res 2017;12:94.

11. Moher D, Liberati A, Tetzlaff J, Altman DG. Preferred reporting items for systematic reviews and meta-analyses: the PRISMA statement. Int J Surg 2010;8:336-41.

12. Poonpet T, Tammachote $\mathrm{R}$, Tammachote $\mathrm{N}$, Kanitnate S, Honsawek S. Association between ADAM12 polymorphism and knee osteoarthritis in Thai population. Knee 2016;23:357-61.

13. Wang L, Guo L, Tian F, Hao R, Yang T. Analysis of single nucleotide polymorphisms within ADAM12 and risk of knee osteoarthritis in a Chinese Han population. Biomed Res Int 2015;2015:518643.

14. Lou S, Zhao Z, Qian J, Zhao K, Wang R. Association of single nucleotide polymorphisms in ADAM12 gene with susceptibility to knee osteoarthritis: a casecontrol study in a Chinese Han population. Int J Clin Exp Pathol 2014;7:5154-9.

15. Shin MH, Lee SJ, Kee SJ, Song SK, Kweon SS, Park DJ, et al. Genetic association analysis of GDF5 and ADAM12 for knee osteoarthritis. Joint Bone Spine 2012;79:488-91.

16. Kerna I, Kisand K, Tamm AE, Lintrop M, Veske K, Tamm AO. Missense single nucleotide polymorphism of the ADAM12 gene is associated with radiographic knee osteoarthritis in middle-aged Estonian cohort. Osteoarthritis Cartilage 2009;17:1093-8.

17. Rodriguez-Lopez J, Pombo-Suarez M, Loughlin J, Tsezou A, Blanco FJ, Meulenbelt I, et al. Association of a nsSNP in ADAMTS14 to some osteoarthritis phenotypes. Osteoarthritis Cartilage 2009;17:321-7.

18. Okada A, Mochizuki S, Yatabe T, Kimura T, Shiomi T, Fujita Y, et al. ADAM-12 (meltrin alpha) is involved in chondrocyte proliferation via cleavage of insulinlike growth factor binding protein 5 in osteoarthritic cartilage. Arthritis Rheum 2008;58:778-89.

19. Seok H, Choi SJ, Yoon J-H, Song GG, Won J-U, Kim $\mathrm{J}-\mathrm{H}$, et al. The Association between Osteoarthritis and Occupational Clusters in the Korean Population: A Nationwide Study. PLoS ONE 2017;12:e0170229.

20. Jones GC, Corps AN, Pennington CJ, Clark IM, Edwards DR, Bradley MM, et al. Expression profiling of metalloproteinases and tissue inhibitors of metalloproteinases in normal and degenerate human achilles tendon. Arthritis Rheum 2006;54:832-42.

21. El Khoury L, Posthumus M, Collins M, Handley CJ, Cook J, Raleigh SM. Polymorphic variation within the ADAMTS2, ADAMTS14, ADAMTS5, ADAM12 and TIMP2 genes and the risk of Achilles tendon pathology: a genetic association study. J Sci Med Sport 2013;16:493-8.

22. Verma P, Dalal K, Chopra M. Pharmacophore development and screening for discovery of potential inhibitors of ADAMTS-4 for osteoarthritis therapy. J Mol Model 2016;22:178.

23. Ji Q, Xu X, Zhang Q, Kang L, Xu Y, Zhang K, et al. The IL-1ß/AP-1/miR-30a/ADAMTS-5 axis regulates cartilage matrix degradation in human osteoarthritis. J Mol Med (Berl) 2016;94:771-85.

24. Mobasheri A, Bay-Jensen AC, van Spil WE, Larkin J, Levesque MC. Osteoarthritis Year in Review 2016: biomarkers (biochemical markers). Osteoarthritis Cartilage 2017;25:199-208. 